\title{
miRNA-1290 Promotes Aggressiveness in Pancreatic Ductal Adenocarcinoma by Targeting IKK1
}

\author{
Na Ta ${ }^{a} \quad$ Xiaoyi Huang ${ }^{a} \quad K^{2}$ ilian Zheng ${ }^{b} \quad$ Yunshuo Zhang ${ }^{a}$ \\ Yisha Gao Lulu Deng $^{a} \quad$ Bingbing Zhang ${ }^{a} \quad$ Hui Jiang ${ }^{a} \quad$ Jianming Zheng ${ }^{a}$ \\ aDepartment of Pathology, Changhai Hospital, Second Military Medical University, Shanghai, \\ 'Department of General Surgery, Changhai Hospital, Second Military Medical University, Shanghai, \\ China
}

\author{
Key Words \\ miRNA • Pancreatic ductal adenocarcinoma $•$ Carcinogenesis $•$ PanIN •IKK1
}

\begin{abstract}
Background/Aims: MicroRNAs (miRNAs) are a group of non-coding RNAs that play diverse roles in pancreatic carcinogenesis. In pancreatic ductal adenocarcinoma (PDAC), NF- $\kappa B$ is constitutively activated in most patients and is linked to a mutation in KRAS via I $\kappa B$ kinase complex 1 (IKK1, also known as IKK $\alpha$ ). We investigated the link between PDAC aggressiveness and miR-1290. Methods: We used miRCURY ${ }^{\mathrm{TM}}$ LNA Array and in situ hybridization to investigate candidate miRNAs and validated the findings with PCR. The malignant behavior of cell lines was assessed with Cell Counting Kit-8, colony formation, and Transwell assays. A dual-luciferase reporter assay was used to evaluate the interaction between miR-1290 and IKK1. Protein expression was observed by western blotting. Results: In this study, 36 miRNAs were dysregulated in high-grade pancreatic intraepithelial neoplasia (PanIN) and PDAC tissues compared with low-grade PanIN tissues. The area under the curve values of miR1290 and miR-31-5p were 0.829 and 0.848 , respectively ( $95 \%$ confidence interval, $0.722-0.936$ and $0.749-0.948$, both $P<0.001)$. There was a significant correlation between miR-1290 and histological differentiation $(P=0.029)$, pT stage $(P=0.006)$, and lymph node metastasis $(P=$ 0.001). In addition, the in vitro work showed that miR-1290 promoted PDAC cell proliferation, invasion, and migration. Western blotting and the dual-luciferase reporter assay showed that miR-1290 promoted cancer aggressiveness by directly targeting IKK1. The synergist effect of miR-1290 on the proliferation and metastasis of PDAC cells was attenuated and enhanced by IKK1 overexpression and knockdown, respectively. Consistent with the in vitro results, a subcutaneous tumor mouse model showed that miR-1290 functioned as a potent promoter of PDAC in vivo. Conclusion: MiR-1290 may act as an oncogene by directly targeting the 3 -untranslated region of IKK1, and the miR-1290/IKK1 pathway may prove to be a novel diagnostic and therapeutic target for PDAC.

$\mathrm{N}$. Ta, X. Huang and K. Zheng contributed equally to this work.




\section{Cellular Physiology Cell Physiol Biochem 2018;51:711-728

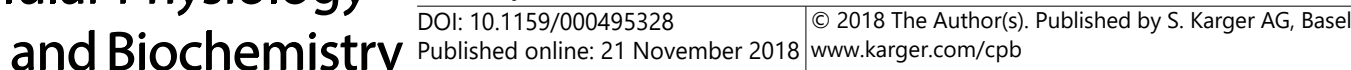 \\ Ta et al.: miR-1290 Promotes PDAC Aggressiveness by Targeting IKK1}

\section{Introduction}

Pancreatic ductal adenocarcinoma (PDAC) is a relatively common malignant tumor of the digestive system, with a 5-year survival rate of less than 5\% in China [1]. Detection of PDAC during the early stages is usually difficult because of its concealable location, early confounding symptoms, and lack of specific biomarkers [2].

Pancreatic intraepithelial neoplasia (PanIN), considered a precursor or initial lesion of PDAC, is classified as PanIN1, PanIN2, and PanIN3 (including carcinoma in situ)[3]. Genetic variations such as those of KRAS, TP53, and CDKN2A can also be found in the initial stage of pancreatic carcinogenesis $[4,5]$, suggesting that the biological process involved in pancreatic carcinogenesis occurs even at early stages. Recently, some biomarkers were proven to be related to the progression of PDAC. Lo et al. [6] reported that the expression of underglycosylated mucin 1 antigen varied from the PanIN stage to the late stages of the disease. Krüppel-like factor 4 is upregulated in PanIN and is essential for acinar-to-ductal metaplasia in the early stage of pancreatic carcinogenesis [7].

MicroRNAs (miRNAs) play important roles in various biological processes, including cell growth, differentiation, proliferation, and metastasis [8-10]. Increasing evidence in recent years suggests that non-coding RNAs, including long non-coding RNAs and miRNAs, are closely related to the development and progression of cancers and that some miRNAs have potential clinical applications [11,12]. Teng and colleagues [13] demonstrated that miR-193a interacts with major vault protein to promote cancer progression by regulating cell cycle and proliferation. Lin et al. [14] found that six circulating miRNAs are correlated with overall survival in castration-resistant prostate cancer. Other studies have reported the molecular function and potential clinical utility of miRNAs in PDAC $[15,16]$. However, the molecular mechanism of miRNAs in pancreatic carcinogenesis remains largely unknown. In this study, in an attempt to elucidate the underlying molecular mechanism, we used miRCURY ${ }^{\mathrm{TM}}$ LNA Array (v.18.0), in situ hybridization, and qRT-PCR to identify miRNAs and compared the selected miRNAs between PanIN and PDAC samples to determine if miR-1290 promotes pancreatic carcinogenesis by directly targeting IкB kinase complex 1 (IKK1, also known as IKK $\alpha$ ).

\section{Materials and Methods}

\section{Patients and clinicopathological characteristics}

This study was approved by the Ethics Committee of Changhai Hospital (Shanghai, China) and conducted in accordance with the Declaration of Helsinki. Written informed consent was obtained from all patients concerned. Altogether, 496 formalin-fixed and paraffin-embedded (FFPE) specimens were obtained from patients who underwent abdominal surgery at Changhai Hospital between 2007 and 2011, including 320 patients with PDAC, 100 patients with chronic pancreatitis, and 76 patients with non-pancreatic diseases. None of the PDAC patients had received any preoperative chemotherapy or radiotherapy. To obtain the PanIN lesion foci, microdissection was used to isolate PanIN lesions in the FFPE specimens. After the microdissection, the specimens were collected in Eppendorf tubes.

\section{RNA extraction and miRNA microarray}

Total RNA was extracted from the FFPE samples by TRIzol (Invitrogen, Carlsbad, CA) according to the manufacturer's protocol and purified with an RNeasy Mini Kit (Qiagen, Hilden, Germany). Plasma RNA was extracted with a miRcute miRNA Isolation Kit (Tiangen, Beijing, China). The total RNA quality was evaluated using the NanoDrop Lite spectrophotometer (Thermo Scientific, Waltham, MA). The miRNA was hybridized on the miRCURY ${ }^{\mathrm{TM}}$ LNA Array (v.18.0) (Exiqon, Vedbaek, Denmark). Quantile normalization was conducted with the GenePix 4000B microarray scanner (Axon, Sunnyvale, CA). Subsequent data analysis was performed by GenePix Pro 6.0 (Molecular Devices, San Jose, CA). Differentially expressed miRNAs were compared between PanIN-3 and normal, PDAC and normal, and PDAC and PanIN-3 tissues. 


\section{Cellular Physiology Cell Physiol Biochem 2018;51:711-728

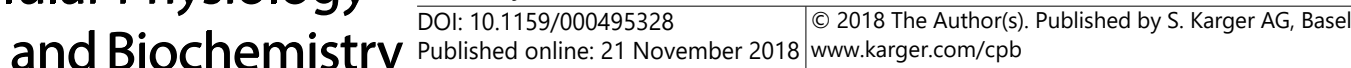

Ta et al.: miR-1290 Promotes PDAC Aggressiveness by Targeting IKK1

In situ hybridization

According to the manufacturer's instructions, Locked Nucleic Acid In Situ Hybridization analysis was performed in 4- $\mu$ m-thick sections of FFPE tissues. After the glass slides with the FFPE tissues were dewaxed and rehydrated, antigen retrieval was performed in $0.01 \mathrm{~mol} / \mathrm{L}$ sodium citrate at $95^{\circ} \mathrm{C}$ for $15 \mathrm{~min}$. The specimens were rinsed for 5 min three times in phosphate-buffered saline (PBS), digested by proteinase $\mathrm{K}$ (Exiqon, Vedbaek, Denmark) at room temperature for $10 \mathrm{~min}$, pre-hybridized in pre-hybridization buffer at $49.5^{\circ} \mathrm{C}$ for $2 \mathrm{~h}$, and hybridized again using an miRNA probe with a glass coverslip in the hybridizer at $55^{\circ} \mathrm{C}$ overnight. The slides were then washed with $5 \times$ saline-sodium citrate (SSC) buffer, $1 \times$ SSC buffer, and $0.2 \times \mathrm{SSC}$ buffer twice for $5 \mathrm{~min}$ each at $55^{\circ} \mathrm{C}$, immersed in $0.3 \% \mathrm{H}_{2} \mathrm{O}_{2}$ and methanol for $10 \mathrm{~min}$, and washed three times with PBS. After being covered by blocking buffer for $1 \mathrm{~h}$, the specimens were incubated with anti-digoxigenin peroxidase Fab fragments for $1 \mathrm{~h}$. The antibody signal was amplified with 4-nitro-blue tetrazolium and 5-bromo-4-chloro-3'-indolyl phosphate substrate (Roche, Mannheim, Germany). DAB was applied to visualize the reaction. A negative probe was used as negative control. The staining intensity was recorded using a four-grade system to reflect staining intensity: 0 , no staining; 1 , weak staining; 2 , moderate staining; and 3, strong staining. A five-grade system was used to reflect the percentage of positive cells: 0 , $<1 \% ; 1,1-25 \% ; 2,25-50 \% ; 3,50-75 \%$; and $4,>75 \%$. According to the total score of the staining intensity plus the percentage of positive cells, PDAC patients were classified into three groups: a negative-expression group (total score, 0 ), a low-expression group (total score, 1), and a high-expression group (total score, $>2$ ).

\section{Quantification of miRNA by $q R T-P C R$}

miRNA levels were quantified by qRT-PCR on a Step One Plus ${ }^{\mathrm{TM}}$ System (Life Technologies, Carlsbad, CA). The reverse transcription reaction was conducted with miRcute cDNA (Tiangen) in a 20- $\mu$ l solution including $2 \mu \mathrm{l}$ Poly(A) reaction agent, $2 \mu \mathrm{l} 10 \times$ RT Primer, $2 \mu \mathrm{l} 10 \times$ RT Buffer, $1 \mu \mathrm{l}$ Super Pure dNTPs $(2.5 \mathrm{mM}$ each), $1 \mu \mathrm{l}$ RNasin ( $40 \mathrm{U} / \mu \mathrm{l}$ ), $0.5 \mu \mathrm{l}$ Quant RTase, and $11.5 \mu \mathrm{l}$ RNase-free $\mathrm{ddH}_{2} \mathrm{O}$. The reaction was conducted at $37^{\circ} \mathrm{C}$ for $60 \mathrm{~min}$. After the reverse transcription reaction, the reverse products were mined with a solution containing SYBR@ Premix Ex Taq ${ }^{\mathrm{TM}}$ (Tli RNaseH Plus) (Takara, Dalian, China). The qRT-PCR reaction was conducted with 45 cycles of $94^{\circ} \mathrm{C}$ for $20 \mathrm{~s}$ and $60^{\circ} \mathrm{C}$ for $34 \mathrm{~s}$.

\section{Cell culture and transfection}

Human PDAC cell lines AsPC-1, BxPC-3, and PANC-1 were purchased from the Institute of Biochemistry and Cell Biology (Chinese Academy of Sciences, Shanghai, China). The culture medium was Dulbecco's modified Eagle's medium (DMEM) (Gibco, Gaithersburg, MD) with 10\% fetal bovine serum (FBS) (Gibco, Gaithersburg, MD) and penicillin and streptomycin. The culture environment was $37^{\circ} \mathrm{C}$ with $5 \% \quad \mathrm{CO}_{2}$. Chemically synthesized miR-1290 agomir, miR-1290 antagomir, IKK1 siRNA, and their corresponding negative controls were purchased from RiboBio Co., Ltd. (Guangzhou, China). The transfection was performed with Lipofectamine® 2000 (Invitrogen) according to the manufacturer's instructions.

\section{Cell viability assays}

For a colony formation assay, cell lines transfected with miR-1290 agomir, miR-1290 antagomir, and their corresponding negative controls were re-suspended in DMEM with 10\% FBS in 6-well plates (200 cells/well) and cultured at $37^{\circ} \mathrm{C}$ with $5 \% \mathrm{CO}_{2}$ for 2 weeks.

For the Cell Counting Kit-8 (CCK-8) assay, the cell proliferation of cell lines transfected with miR-1290 agomir, miR-1290 antagomir, and their corresponding negative controls was assessed with CCK-8 (Dojindo, Kumamoto, Japan). After transfection, the transfected cell lines were seeded in 96-well plates and cell proliferation was monitored every $24 \mathrm{~h}$ for 3 days. The number of viable cells was determined by Epoch (BioTek, Winooski, VT) by the absorbance at $450 \mathrm{~nm}$.

\section{Wound-healing assay}

Cell lines transfected with miR-1290 agomir, miR-1290 antagomir, and their corresponding negative controls were seeded in 6-well plates. When the cell confluence reached $95 \%$, the cells were wounded by a scratch with a $200-\mu \mathrm{L}$ pipette tip. The width of the wound was measured at 0,12 , and $24 \mathrm{~h}$. 


\section{Cellular Physiology Cell Physiol Biochem 2018;51:711-728

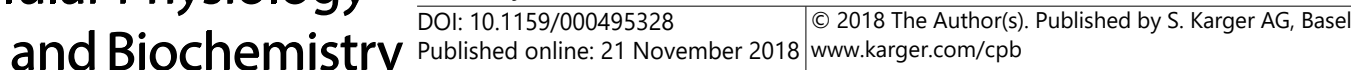 \\ Ta et al.: miR-1290 Promotes PDAC Aggressiveness by Targeting IKK1}

\section{Transwell invasion and migration assays}

Transwell invasion and migration assays were evaluated by Transwell permeable supports (Corning Costar, Corning, NY). In the invasion assay, the upper side of the membrane was covered with $40 \mu \mathrm{l}$ Matrigel. After transfection with miR-1290 agomir, miR-1290 antagomir, and their corresponding negative controls, the cell lines were seeded in the upper chambers with serum-free DMEM medium; $500 \mu$ DMEM with 20\% FBS was placed in the lower chambers. After 2 days, the cells remaining on the upper side of the membrane were removed with cotton swabs, and the cells in the lower chambers were fixed by paraformaldehyde and stained with crystal violet. The cell number was counted using a microscope.

\section{Western blot}

After transfection, cells were lysed with RIPA buffer (Beyotime, Haimen, China) and complete protease inhibitor cocktail (Biotool, Houston, TX). After ultrasonic pyrolysis, the protein concentration was determined with a BCA Protein Assay Kit (Beyotime). The protein samples were then subjected to sodium dodecyl sulfate-polyacrylamide gel electrophoresis electrophoresis. The membrane was blocked in 5\% fat-free milk for $2 \mathrm{~h}$, incubated in the primary antibody (anti-IKK, Abcam, Cambridge, MA; anti-GAPDH, Proteintech, Chicago, IL), and washed three times for 5 min each with PBS. After washing, the secondary goat anti-mouse IgG antibody (Jackson ImmunoResearch Laboratories, West Grove, PA) was used at room temperature for $2 \mathrm{~h}$. The enhanced chemiluminescence system (GE Healthcare, Chicago, IL) was applied to detect the results.

\section{Dual-luciferase reporter assay}

To detect whether miR-1290 directly regulated the expression of IKK1 by interacting with the 3'-untranslated region (UTR) of IKK (Biosune, Shanghai, China), we synthesized wild-type and mutant 3'UTR by chemosynthesis and amplified them by PCR. The PCR products were inserted into the psiCHECK-2 vector with XhoI and NotI restriction sites. HEK-293T cells were co-transfected with the recombinant plasmids. Four kinds of plasmids were used in this assay: IKK-MUT (mutation), IKK-WT (wild-type), miR1290 agomir, and miR-1290 antagomir. Renilla luciferase activity was used as a reference. The results were obtained with an illuminometer (Berthold, Bad Wildbad, Germany).

\section{Xenograft models}

To evaluate the effects of miR-1290 on cancer growth in vivo, we injected the transfected cell linesBxPC-3 cells with miR-1290 agomir, BxPC-3 cells with miR-1290 antagomir, and their corresponding negative controls-into nude mice ( $n=6$ in each group). The subcutaneous tumor size was measured every 5 days and the tumors were incised after 25 days. The tumor volume was measured according to the following equation: (long axis $\times$ short $\operatorname{axis}^{2}$ ) $/ 2$.

\section{Statistical analyses}

All statistical analyses were performed using SPSS 13.0 statistical software (SPSS, Inc., Chicago, IL). Differences in miRNAs between high-grade PanIN and low-grade PanIN were analyzed by the chi-square test. Differences in the expression of circulating miRNAs between the PDAC specimens were analyzed by a t-test. Results are expressed as the mean \pm standard deviation, and comparisons between groups were evaluated by one-way analysis of variance or t-test. P values $<0.05$ were considered statistically significant and all tests were two-tailed.

\section{Results}

miRNAs are dysregulated in PanIN and PDAC

Using the miRCURY' ${ }^{\mathrm{TM}}$ LNA Array (v.18.0) (Exiqon), 3100 miRNAs were identified in the PanIN and PDAC tissues of 48 patients; of these, 36 miRNAs were significantly dysregulated in PanIN-3 tissues compared with those in normal ductal tissues (fold change $>5, \mathrm{P}<0.05$ ) (Table 1). To validate the expression of the miRNAs, in situ hybridization was performed in PanIN-1, PanIN-3, and PDAC tissues for 19 selected miRNAs (miR-31-5p, miR-29a-5p, miR-21-5p, miR-200b-3p, miR-192-5p, miR-146b-5p, miR-1290, miR-101-3p, let-7a-5p, miR-196a-3p, miR-29a-3p, miR-34a-3p, miR-155, miR-105-3p, miR-216a-5p, miR-218-2-3p, 


\section{Cellular Physiology Cell Physiol Biochem 2018;51:711-728

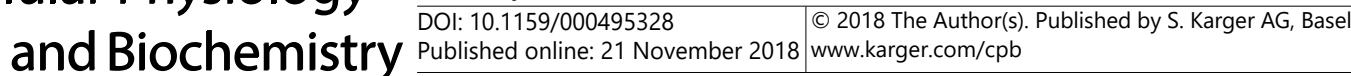 \\ Ta et al.: miR-1290 Promotes PDAC Aggressiveness by Targeting IKK1}

miR-34a-5p, miR-513c-3p, and miR-887). The clinical characteristics of the PDAC patients are summarized in Table 2. The expression levels of six miRNAs-miR-31-5p, miR-1013p, miR-1290, miR-34a-3p, miR-21-5p, and miR-155-underwent significant changes in PanIN-3 and PDAC tissues compared with PanIN-1 tissues $(P<0.05)$. Representative results are shown in Fig. 1. Furthermore, differences in the expression levels of miRNAs between low-grade and high-grade PanINs were also examined. Chi-square test results showed that the expression levels of these six miRNAs were significantly higher in highgrade PanIN than in low-grade PanIN (miR31-5p: $\mathrm{P}=0.034$; miR-101-3p: $\mathrm{P}=0.044$; miR1290: $\mathrm{P}=0.037$; miR-34a-3p: $\mathrm{P}=0.046$; miR21-5p: $\mathrm{P}=0.023$; miR-155: $\mathrm{P}=0.016$ ). The details are shown in Table 3.

miR-1290 is associated with the clinical characteristics of PDAC patients

To identify the potential diagnostic value of miRNAs, the circulating levels of the selected miRNAs were determined in another 40 PDAC patients and 32 patients without any cancers. The clinical characteristics of the patients and plasma levels of the six miRNAs are summarized in Table 4 . The circulating expression levels of miR-31-5p, miR-101-3p, miR-1290, miR-34a-3p, miR-21-5p, and miR155 were significantly upregulated in PDAC patients compared with non-cancerous patients (miR-31-5p: $\mathrm{P}=0.001 ; \mathrm{miR}-101-3 \mathrm{p}: \mathrm{P}=0.001$; miR-1290: $\mathrm{P}<0.001$; miR-34a-3p: $\mathrm{P}$ $=0.005 ; \mathrm{miR}-21-5 \mathrm{p}: \mathrm{P}=0.001 ; \mathrm{miR}-$ 155: $\mathrm{P}=0.020$ ).

To identify the diagnostic value of circulating miRNAs, receiver operating characteristic (ROC) curve analysis was performed by summarizing all of the relative expressions of the cancer and noncancer samples. The results are shown in Fig. 2. The area under the curve (AUC) results suggested that circulating miR-1290 and miR31-5p may be potential diagnostic biomarkers of PDAC.

Additionally, the correlation between the expression of circulating miR-1290 and the clinical characteristics of the patients was analyzed, with a significant correlation between miR-1290 and histological differentiation $(P=0.029)$, pT stage $(P=0.006)$, and lymph node metastasis $(P=0.001)$ (Table 5). The results suggest that miR-1290 may be a potential biomarker of PDAC.

Table 1. The 36 significantly dysregulated miRNAs in PanIN-3 tissues by miRCURY' ${ }^{\mathrm{TM}}$ LNA Array (fold change $>5, P<0.05$ )

\begin{tabular}{ll}
\hline Upregulated miRNA & Downregulated miRNA \\
\hline miR-31-5p & miR-3122 \\
miR-142 & miR-618 \\
miR-101-3p & miR-23c \\
miR-29b-3p & miR-218-3p \\
miR-17-5p & miR-154-5p \\
miR-200b-3p & miR-216a-5p \\
miR-192-5p & miR-548a-5p \\
miR-195-5p & miR-27b-5p \\
let-7g-5p & miR-411-3p \\
miR-93-5p & let-7g-3p \\
miR-21 & miR-521 \\
miR-155 & miR-197-3p \\
miR-93-5p & miR-144-3p \\
miR-3175 & miR-27b-5p \\
miR-146b-5p & \\
miR-15a-5p & \\
let-7c & \\
miR-1290 & \\
miR-126-3p & \\
miR-142-5p & \\
miR-16-5p & \\
miR-342-3p & \\
miR-15a-5p & \\
\hline
\end{tabular}

Table 2. Characteristics of PDAC patients including in situ hybridization variables

\begin{tabular}{lll}
\hline Variables & Number of cases & Percentage (or mean) \\
\hline Total & 17 & $100 \%$ \\
Sex & & \\
Male & 9 & 52.9 \\
Female & 8 & 47.1 \\
Age, years & 17 & $54.6(38-73)$ \\
Tumor stage & & \\
Tis-T2 & 16 & 94.12 \\
T3-T4 & 1 & 5.88 \\
Histologic differentiation & \\
Good and moderate & 12 & 70.59 \\
Poor & 5 & 29.41 \\
Location & & \\
Head & 10 & 58.82 \\
Body and tail & 7 & 41.18 \\
Lymph node metastasis & \\
Present & 4 & 23.53 \\
Absent & 13 & 76.47 \\
Metastasis & & \\
Present & 0 & 0 \\
Absent & 17 & 100 \\
\hline
\end{tabular}


Fig. 1. The result of in situ hybridization of selected miRNAs. (A) miR-31-5p. (B) miR-101-3p. (C) miR1290. (D) miR-34a-3p. (E) miR-215p. (F) miR-155.

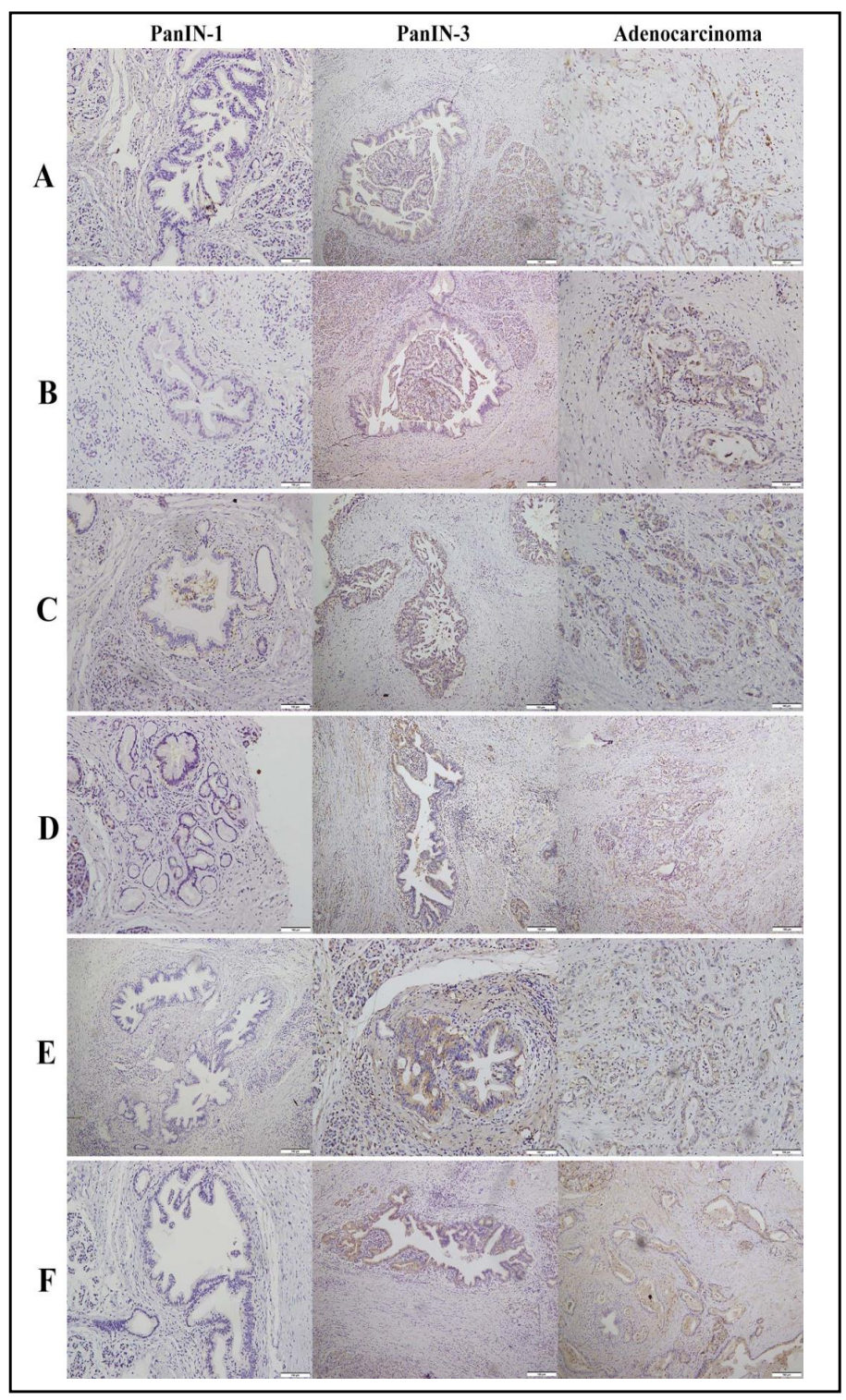

Table 3. Expression levels of selected miRNAs between low-grade and high-grade PanINs

\begin{tabular}{llllll}
\hline miRNAs & PanIN grade & Total lesions & Weakly positive (\%) & Strongly positive (\%) & P value \\
\hline \multirow{2}{*}{ miR-31-5p } & Low & 132 & $5(3.8)$ & $62(47.0)$ & 0.034 \\
& High & 32 & $7(21.9)$ & $24(75.0)$ & $10(8.7)$ \\
miR-101-3p & Low & 115 & $6(5.2)$ & $30(85.6)$ & 0.044 \\
& High & 35 & $3(8.6)$ & $8(5.7)$ & \\
miR-1290 & Low & 140 & $4(2.9)$ & $27(87.1)$ & 0.037 \\
& High & 31 & $1(4.2)$ & $30(23.3)$ & 0.046 \\
miR-34a-3p & Low & 129 & $11(8.5)$ & $20(83.3)$ & 0.023 \\
miR-21-5p & High & 24 & $1(4.2)$ & $59(44.7)$ & \\
\multirow{2}{*}{ miR-155 } & High & 33 & $30(22.7)$ & $28(84.8)$ & 0.016 \\
\hline
\end{tabular}


Upregulation of $\mathrm{miR}$ 1290 promotes cell proliferation in vitro and in vivo

The results of the CCK8 assay suggested that cell proliferation was increased in the miR-1290 agomirtransfected AsPC-1 cell line $(\mathrm{P}<0.05)$, whereas proliferation remained largely unchanged in miR1290 antagomir-transfected AsPC-1 cells (Fig. 3A and B). Similarly, the colony formation assay showed that overexpression of miR1290 agomir increased the proliferation of AsPC-1 cells compared with normal AsPC-1 cells (Fig. 3C). Thus, the cell viability assays suggested that miR-1290 increased cell proliferation. Consequently, the effect of miR-1290 on pancreatic carcinogenesis xenografts was validated via the transfection of nude mice with the PDAC cell line BxPC-3 with miR-1290 agomir and antagomir and their corresponding negative controls. After 25 days, the mice were sacrificed and the tumor volumes were measured (Fig. 3D). Compared with the negative control, tumor growth was significantly accelerated in nude mice injected with miR1290 agomir-transfected BxPC3 cells: the tumor volume was $227.17 \pm 70.93 \mathrm{~mm}^{3}$ in mice injected with miR-1290 agomirtransfected BxPC-3 cells versus $116.25 \pm 37.60 \mathrm{~mm}^{3}$ in mice injected with negative controltransfected BxPC-3 cells $(\mathrm{P}=$ 0.007) (Fig. 3E). In contrast, tumor growth was significantly delayed in nude mice injected with miR-1290 antagomirtransfected BxPC-3 cells: the tumor volume was $94.83 \pm 24.37$ $\mathrm{mm}^{3}$ in mice injected with miR1290 antagomir-transfected BxPC-3 cells versus $158.25 \pm 54.23 \mathrm{~mm}^{3}$ in mice injected with negative control-transfected BxPC-3 cells $(\mathrm{P}=0.026)$ (Fig. 3E).
Table 4. Clinical characteristics of patients and plasma levels of the six miRNAs

\begin{tabular}{llll}
\hline Variables & Pancreatic cancer group & Non-cancerous group & P value* \\
\hline Sex & & & \\
Male & 25 & 13 & 0.0961 \\
Female & 15 & 19 & \\
Age, years & & & \\
$>60$ & 21 & 23 & 0.0542 \\
$\leq 60$ & 19 & & \\
Differentiation & & - & - \\
Good and moderate & 7 & - & \\
Poor & 33 & - & - \\
pT stage & & - & \\
Tis-T2 & 24 & & \\
T3-T4 & 16 & - & \\
Lymph node metastasis & - & \\
Present & 11 & - & \\
Absent & 29 & - & \\
Metastasis & & & \\
Present & 5 & $0.65 \pm 0.32$ & 0.001 \\
Absent & 35 & $0.07 \pm 0.05$ & 0.001 \\
Relative expression levels of miRNAs (mean \pm SD) & \\
miR-31-5 & $2.53 \pm 0.40$ & $0.74 \pm 0.29$ & $<0.001$ \\
miR-101-3 & $23.52 \pm 6.68$ & $0.13 \pm 0.12$ & 0.005 \\
miR-1290 & $45.99 \pm 11.29$ & $1.18 \pm 0.44$ & 0.001 \\
miR-34a-3p & $2.01 \pm 0.62$ & & \\
miR-21-5p & $5.78 \pm 1.18$ & & \\
miR-155 & $46.35 \pm 18.52$ & & \\
\hline
\end{tabular}

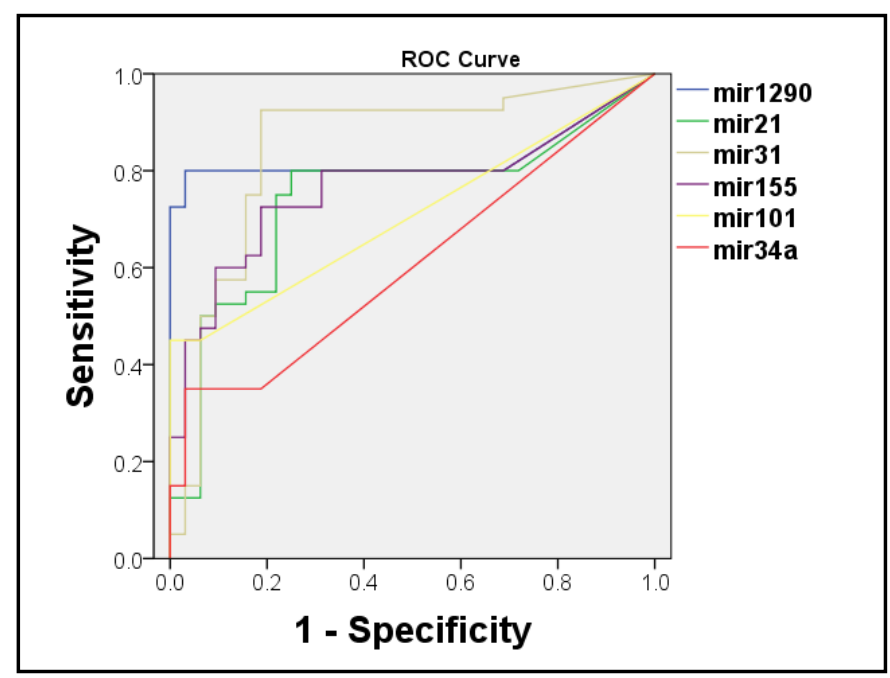

Fig. 2. Assessment of the diagnostic value of selected circulating miRNAs-miR-31-5p, miR-101-3p, miR-1290, miR-34a-3p, miR21-5p, and miR-155-by ROC curve. The AUC values of miR1290 and miR-21-5p were 0.829 and 0.742 , respectively (95\% confidence interval (CI), 0.722-0.936 and 0.622-0.862, both $\mathrm{P}<0.001)$. The AUC values of miR-31-5p and miR-155 were 0.848 and 0.766 , respectively (95\% CI, $0.749-0.948$ and $0.652-0.879$, both $\mathrm{P}<0.001$ ). The AUC values of miR-101-3p and miR-34a-3p were 0.708 and 0.608 , respectively (95\% CI, 0.589-0.827 and 0.478-0.738, both $\mathrm{P}=0.118$ ). 


\section{Cellular Physiology Cell Physiol Biochem 2018;51:711-728 and Biochemistry Published $\begin{aligned} & \text { DOI } 10.1159 / 000495328 \\ & \text { (c) } 2018 \text { The Author(s). Published by S. Karger AG, Basel } \\ & \text { www.karger.com/cpb }\end{aligned}$ Ta et al.: miR-1290 Promotes PDAC Aggressiveness by Targeting IKK1}

miR-1290 increases cell invasion and migration in vitro Knowing that the expression level of circulating miR-1290 is closely associated with lymph node metastasis, we attempted to clarify the effect of miR-1290 on the invasion and migration of pancreatic cell lines by transfecting the PANC-1 and AsPC-1 cell lines with miR-1290 agomir and antagomir and their corresponding negative controls and observing the effect on cell invasion and migration using wound-healing and Transwell assays. As shown in Fig. S1 (For all supplemental material see www.karger. com / $10.1159 / 000495328$ ), the migration of AsPC-1 cells transfected with miR-1290 agomir was significantly increased compared with that of AsPC1 cells transfected with the negative control. In contrast, the migration of PANC-1 cells transfected with miR-1290 antagomir was significantly decreased compared with that of the negative control (Fig. S1). As we previously predicted, the Transwell migration assay showed higher numbers of AsPC-1 cells transfected with miR-1290 agomir but lower numbers of PANC-1 cells transfected with miR-1290 antagomir (Fig. 4A): $336.00 \pm 76.64$ AsPC-1 cells transfected with miR-1290 agomir versus $63.75 \pm 6.24$ AsPC-1 cells transfected with miR1290 negative control $(\mathrm{P}<0.001)$ and $16.25 \pm 4.43$ PANC-1 cells transfected with miR-1290 antagomir versus $33.25 \pm 8.26$ PANC-1 cells transfected with miR-1290 negative control $(P=0.002)$. In addition, the invasion assay suggested that miR-1290 agomir increased the invasion ability of AsPC-1 cells and that the invasion ability was reduced in PANC-1 cells transfected with miR-1290 antagomir: $12.50 \pm 1.73$ AsPC-1 cells transfected with miR-1290 agomir versus $4.25 \pm 1.26$ AsPC-1 cells transfected with miR-1290 negative control $(\mathrm{P}<$ 0.001 ) and $19.50 \pm 4.20$ PANC-1 cells transfected with miR-1290 antagomir versus $42.75 \pm$ 14.29 PANC-1 cells transfected with miR-1290 negative control $(\mathrm{P}=0.038)$. The cell numbers of the Transwell assays are shown in Fig. S2.

miR-1290 directly targets the 3'-UTR of IKK1

The TargetScan, miRDB, and miRanda databases were used to explore the targets of miR-1290 (Fig. 5A). Among the 70 genes identified, IKK1 was selected to measure its effect on PDAC (Fig. 5B). The expression level of IKK1 was detected by western blot in AsPC-1 cells transfected with miR-1290 agomir and agomir negative control. As we predicted, the expression of IKK1 was significantly decreased in AsPC-1 cells transfected with miR-1290 agomir compared with negative control (Fig. 5C). To reveal the interaction of miR-1290 and IKK1, a dual-luciferase reporter assay was used. The results showed that miR-1290 agomir decreased the relative luciferase activity in the 3'-UTR of IKK1 vector compared with negative control $(\mathrm{P}<0.05)$. In contrast, the luciferase activity was increased in the 3 '-UTR of IKK1 vector transfected with miR-1290 antagomir compared with negative control (P $<0.05$ ) (Fig. 5D). Thus, our results suggest that miR-1290 suppressed IKK1 expression by directly targeting its 3'-UTR.

\section{IKK1 silencing increases PDAC aggressiveness}

To validate the effect of IKK1 on pancreatic carcinogenesis, IKK1 siRNA was transfected into AsPC-1 and PANC-1 cells. IKK1 silencing significantly increased the proliferation, migration, and invasion abilities of PDAC cells (Fig. 6A and B), which was consistent with the result of the wound-healing assay (Fig. S3). These results suggest that IKK1 silencing has the same effect on PDAC cells as miR-1290 overexpression. 


\section{Cellular Physiology Cell Physiol Biochem 2018;51:711-728

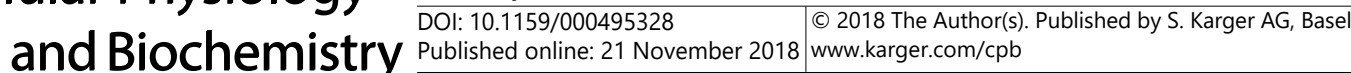 Ta et al.: miR-1290 Promotes PDAC Aggressiveness by Targeting IKK1}

Expression of IKK1 restores the suppressive function of miR-1290

We next ectopically expressed miR-1290 agomir and recombinant IKK1 without the 3'UTR of IKK1 in AsPC-1 and PANC-1 cells. The CCK-8 assay showed that IKK1 significantly decreased the proliferation of both cell lines with miR-1290 agomir (Fig. 7A). Transwell invasion and migration assays showed that IKK1 expression decreased the invasion and migration abilities of AsPC-1 and PANC-1 cells (Fig. 7B and C). These results indicate that expression of IKK1 restored the suppressive function of miR-1290 in PDAC.

Fig. 3. (A) CCK-8 results of the AsPC-1 cell line transfected with miR-1290 agomir and the corresponding negative control. (B) CCK-8 results of the PANC-1 cell line transfected with miR1290 antagomir and the corresponding negative control. (C) Colony formation assay results. I, AsPC1 cell line transfected with miR-1290 agomir; II, AsPC-1 cell line transfected with miR1290 agomir negative control; III, AsPC-1 cell line without any treatment. (D) Effects of miR-1290 on PDAC in vivo. Nude mice were sacrificed after injection with BxPC3 cells transfected with miR-1290 agomir (or miR-1290antagomir and their negative control). (E) His to pathological phenotype and IKK1 expression results of the xenograft models. (F) The tumor volume was larger in nude mice injected with BxPC-3 cells transfected with miR-
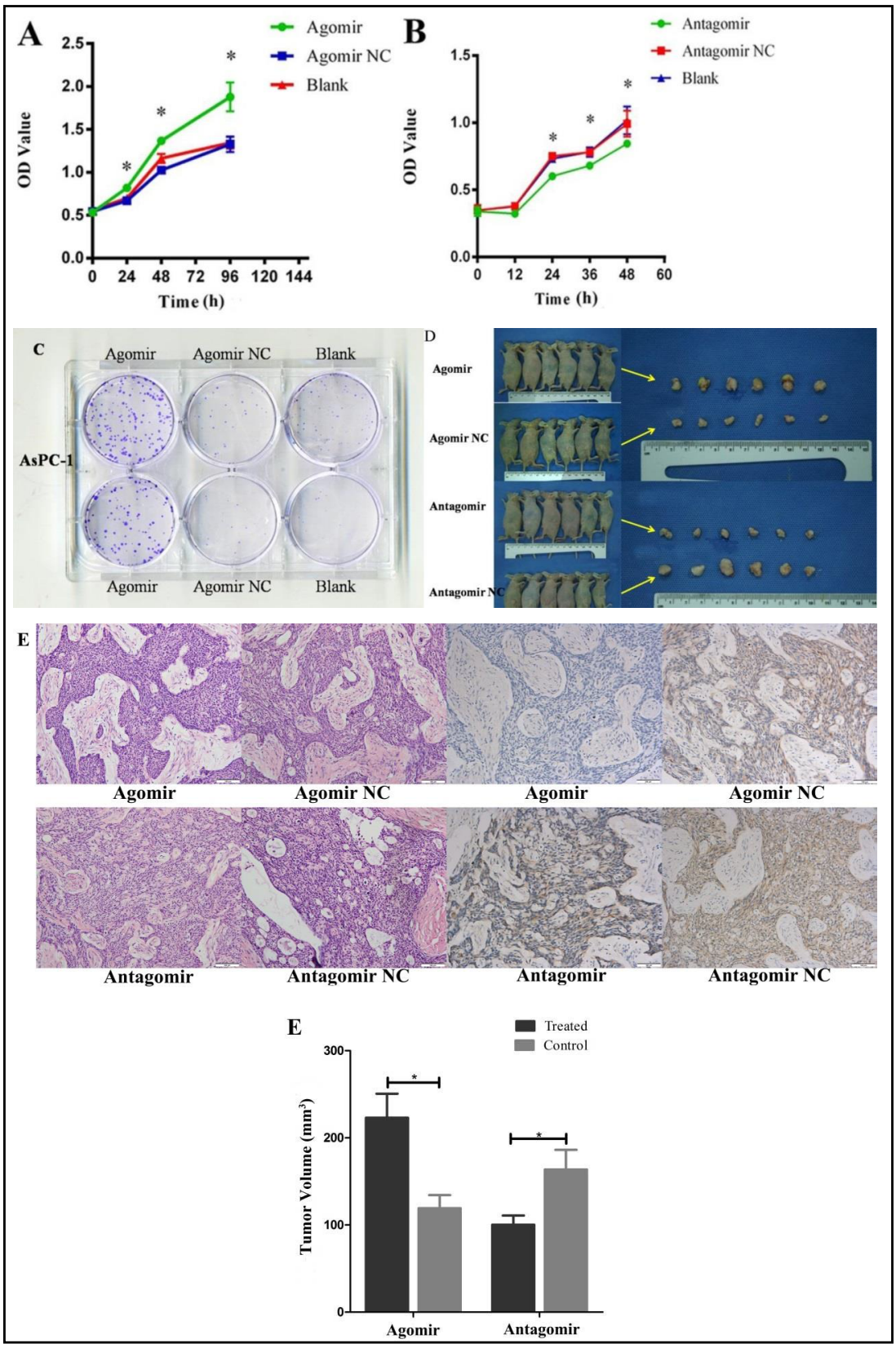
1290 agomir (Treated)

than in nude mice transfected with miR-1290 agomir negative control (Control) $(\mathrm{P}=0.007)$. The tumor volume was larger in nude mice injected with BxPC-3 cells transfected with miR-1290 antagomir (Treated) than in nude mice transfected with miR-1290 antagomir negative control (Control) $(\mathrm{P}=0.026)$. 


\section{Cellular Physiology}

and Biochemistry

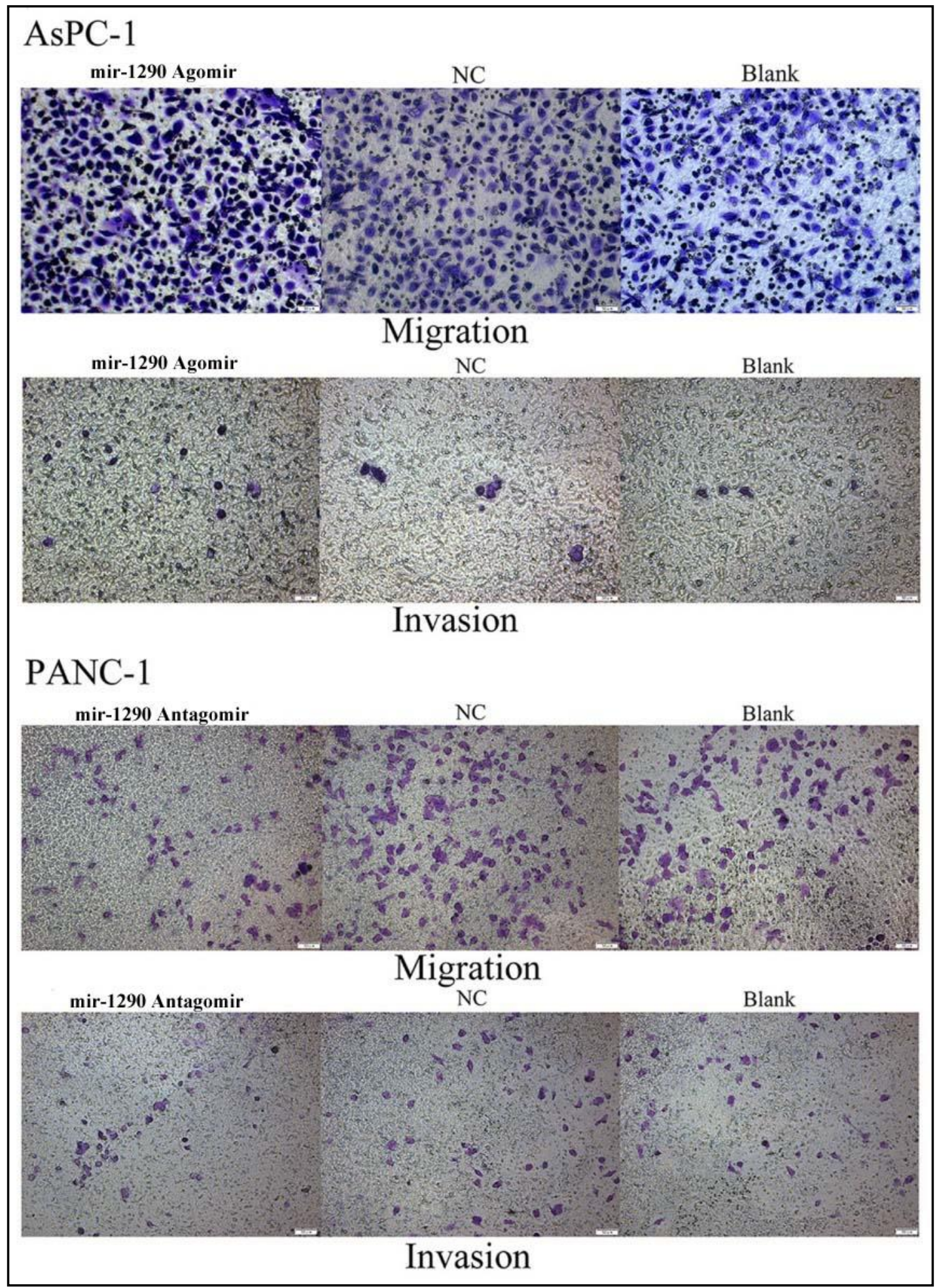

Fig. 4. Transwell migration and invasion assays of cancer cells transfected with miR-1290 agomir. NC, cancer cells transfected with miR-1290 agomir negative control; Blank, cancer cells without any treatment. 
Fig. 5. (A and $B$ ) The bioinformatics results of TargetScan, miRDB, and miRanda in predicting the target genes of miR1290. (C) Western blotting results for IKK1 in AsPC1 cells transfected with miR-1290 agomir, agomir negative control, and not transfected (blank) and in PANC-1 cells transfected with miR-1290 antagomir, antagomir negative control (NC), and not transfected (Blank). (D) Dual-luciferase reporter assay results. The miR1290 agomir decreased the relative luciferase activity in the 3'-UTR of IKK1 vector compared with negative control (NC). The miR-1290 antagomir decreased the relative luciferase activity in the 3'-UTR of IKK1 vector compared with negative control (NC).

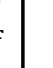

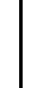

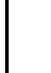

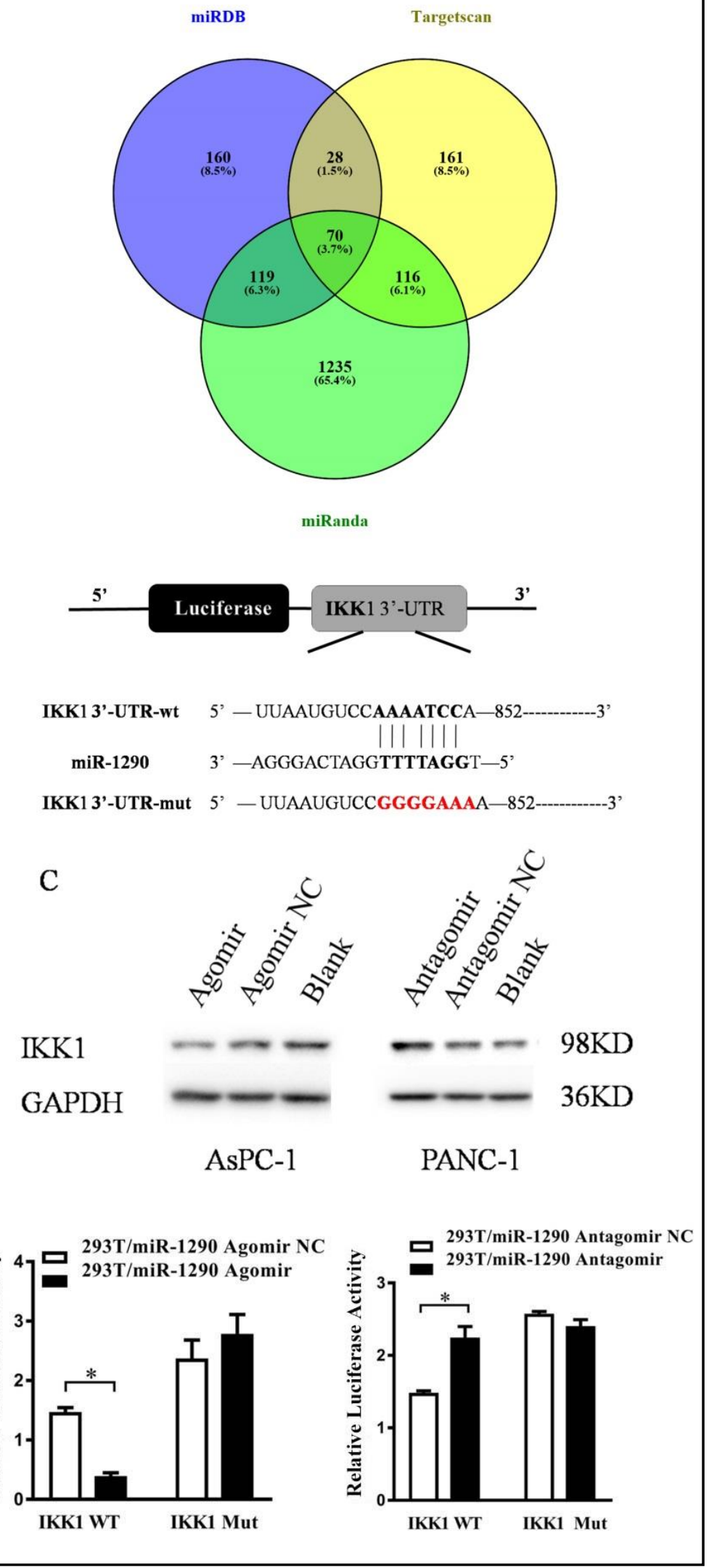


Fig. 6. IKK1 silencing increases PDAC aggressiveness. (A) Proliferation curves of the indicated cancer cell lines upon $24 \mathrm{~h}$ from transfection with the IKK1 siRNA. (B) Transwell migration and invasion assays showing an increase in cellular migration and invasion with IKK1 siRNA transfection.
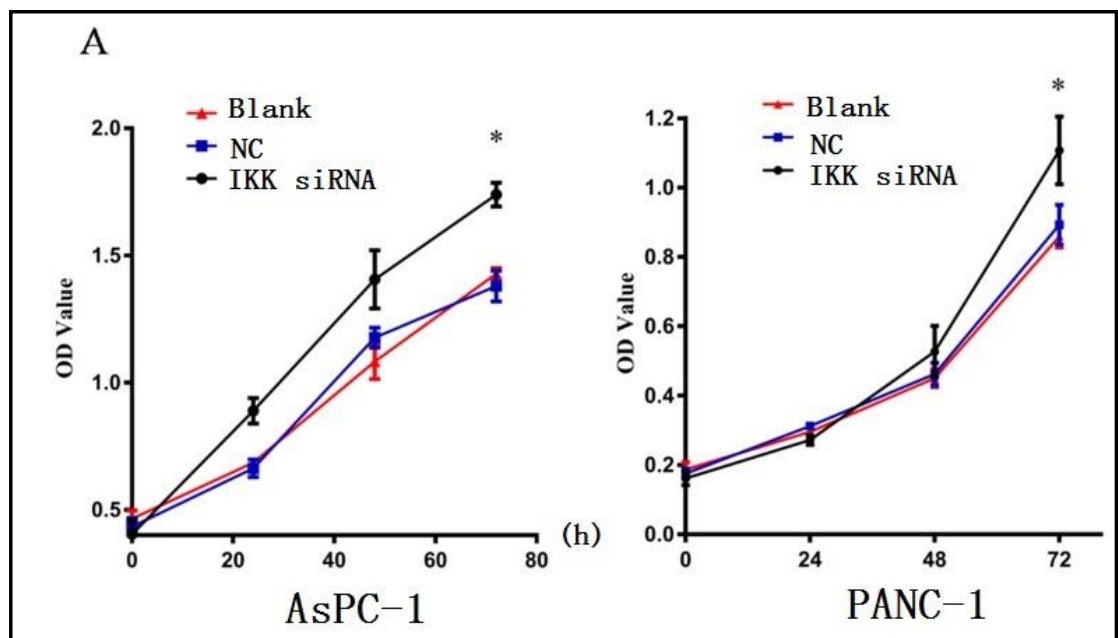

B

\section{AsPC-1}
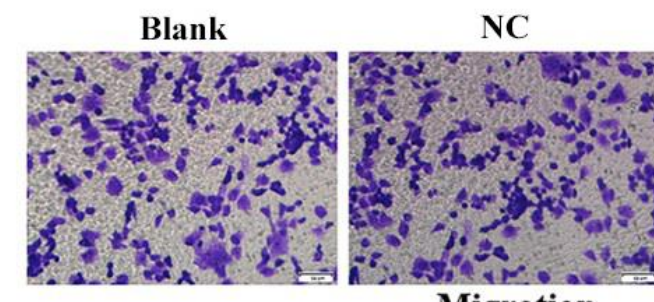

Migration
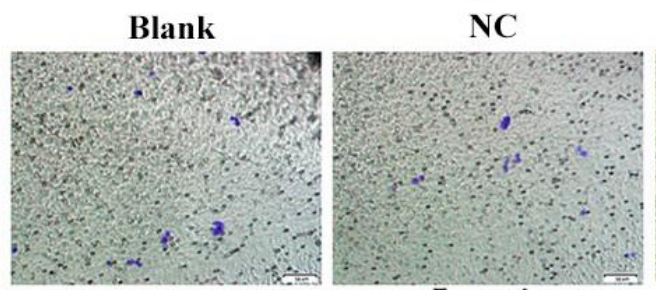

IKK1 siRNA

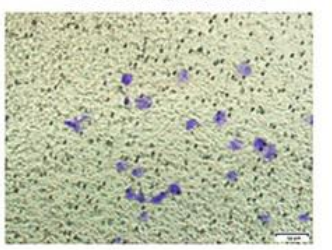

PANC-1
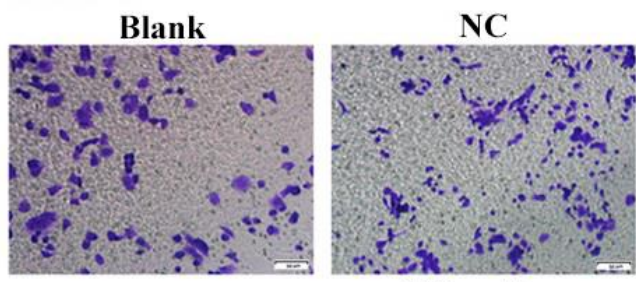

IKK1 siRNA

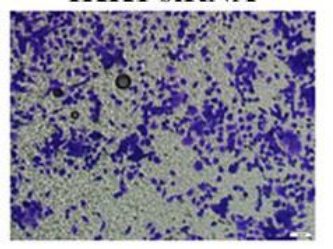

Migration

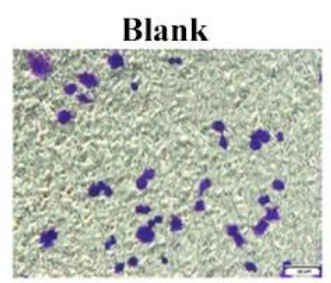

NC

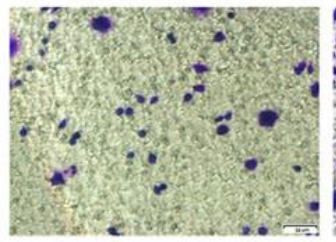

IKK1 SiRNA

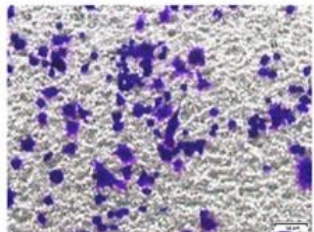

Invasion 


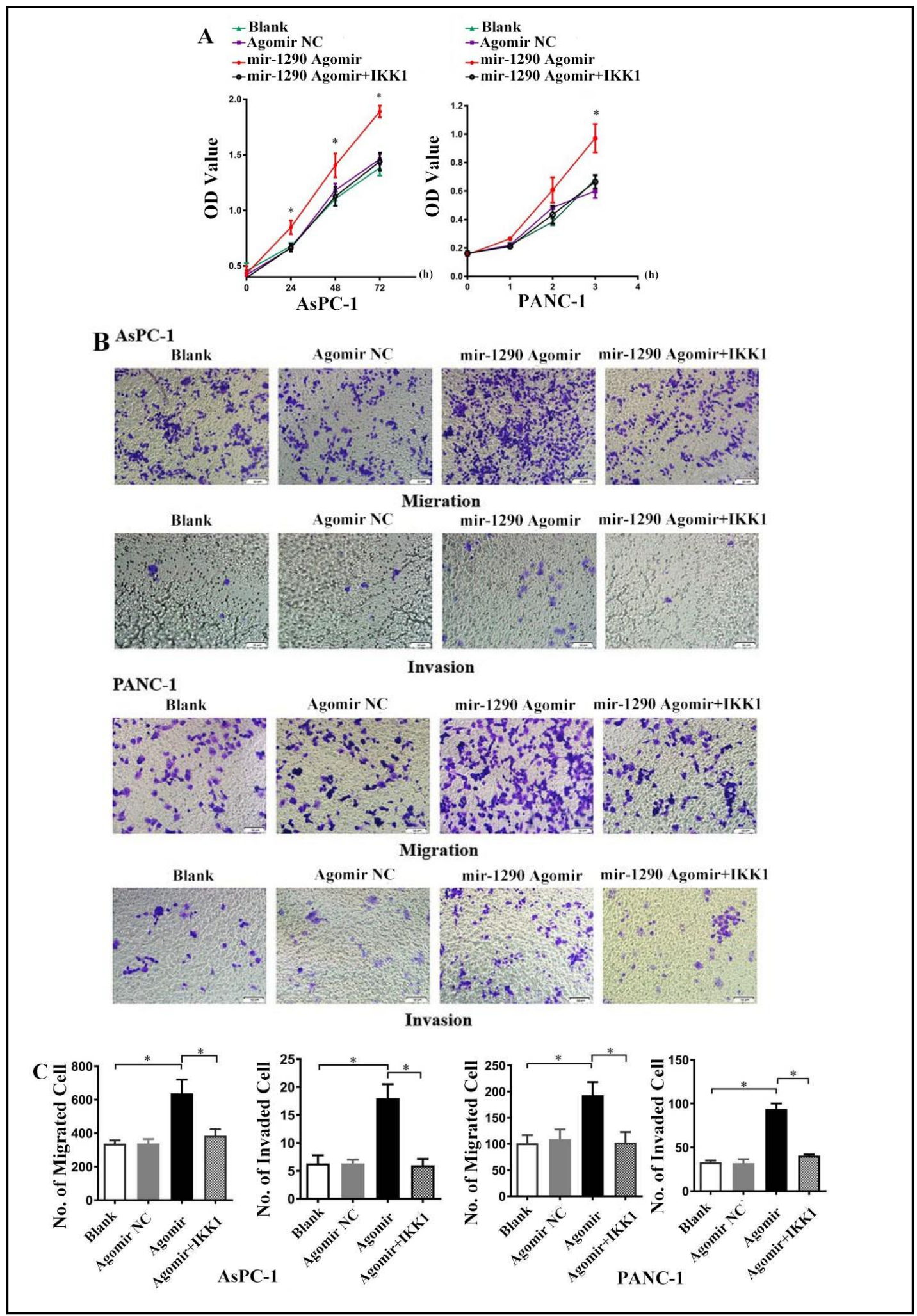

Fig. 7. IKK1 restores the suppressive function of miR-1290. (A) Proliferation curves of the indicated cancer cell lines transfected with IKK1 without the 3'-UTR showed inhibited proliferation in cancer cell lines. (B and C) Transwell migration and invasion assays showed that IKK1 inhibited the migratory and invasive effects of miR-1290. Columns represent the mean \pm standard deviation. ${ }^{*} \mathrm{P}<0.05$.

\section{KARGER}




\section{Cellular Physiology Cell Physiol Biochem 2018;51:711-728

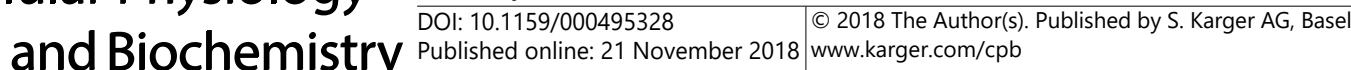 \\ Ta et al.: miR-1290 Promotes PDAC Aggressiveness by Targeting IKK1}

\section{Discussion}

Non-invasive biomarkers are urgently required to detect early PDAC and thereby decrease the morbidity and improve the survival of PDAC patients. MicroRNAs are a group of novel molecules that have been identified as biomarkers of many kinds of cancers. Some studies [17-21] reported that differences in the expression profiles of circulating miRNAs could be used as biomarkers to differentiate PDAC patients from healthy individuals. However, the number of circulating miRNAs that can be used to detect PDAC is relatively small compared with miRNAs identified by microarray, which behooves researchers to find more useful miRNAs as diagnostic biomarkers and uncover the molecular mechanism underlying pancreatic carcinogenesis.

In this study, we used a miRCURY ${ }^{\mathrm{TM}}$ LNA Array to identify differentially expressed miRNAs in normal, PanIN, and PDAC tissues and found that the expression of 36 miRNAs underwent significant changes in PanIN tissues compared with normal tissues. To validate the microarray results, in situ hybridization of 19 selected miRNAs was performed in PanIN-1, PanIN-3, and PDAC tissues from 20 paraffin blocks. The overall expression levels of six miRNAs-miR-315p, miR-101-3p, miR-1290, miR-34a-3p, miR-21-5p, and miR-155-underwent significant changes in PanIN-3 and PDAC tissues compared with PanIN-1 tissues, suggesting that some miRNAs were involved in the early stage of pancreatic carcinogenesis. These six circulating miRNAs could be used to differentiate PDAC patients from non-cancerous individuals with an AUC > 0.7. Consistent with previous studies [22, 23], we found that miR-21-5p and miR155 were abnormally expressed in PDAC tissues and precursor lesions. In addition, miR196b, miR-145, miR-217, and miR-148a also underwent remarkable changes in PanINs [2426], suggesting that these miRNAs may be novel biomarkers to detect PDAC at early stages.

We also conducted PCR to identify whether the circulating expression levels of the six miRNAs could be used as diagnostic biomarkers of PDAC. The ROC curve indicated that miR-1290 and miR-31-5p had potential diagnostic value for screening PDAC. However, to improve the specificity and sensitivity for the diagnosis of pancreatic cancer, multiple strategies and steps are necessary because a single biomarker may be dramatically altered in many kinds of cancers. Indeed, the expression level of miR-1290 is also increased in the blood samples of patients with other types of cancer. Imaoka et al [27], using miRNA array analysis, found that a high serum level of miR-1290 was correlated with aggressiveness and poor prognosis in colorectal cancer. Nagamitsu and colleagues [28] reported that circulating miR-1290 was increased in cervical cancer patients compared with healthy controls. Given the variable plasma expressions of miRNA, it would be sensible to combine several miRNAs and other serum biomarkers to comprehensively screen PDAC. Consequently, we focused on the association between plasma miR-1290 and the clinical characteristics of the patients and found that a high expression of miR-1290 was correlated with histological differentiation, pT stage, and lymph node metastasis, indicating that miR-1290 played a key role in the progression of PDAC. In 2013, a similar study conducted by Li and colleagues [29] revealed that miR-1290 expression was elevated in low-stage PDAC patients and that a high level of miR-1290 was associated with poor PDAC prognosis. Conclusively, miR-1290 participates in the initiation and progression of PDAC and precursor lesions. Thus, miR-1290 has a potential diagnostic and prognostic value in PDAC.

The molecular mechanisms of PDAC have been investigated for several decades. Pancreatic carcinogenesis is a complex pathophysiological process involving many signal transduction pathways, such as KRAS, TGF- $\beta$, hedgehog, and Wnt/catenin [30-33]. In recent years, some miRNAs were found to interact with molecules related to these pathways during PDAC development and progression. Keklikoglou et al [34] demonstrated that miR-206 suppressed NF- $\kappa B$ transcriptional activity by directly interacting with KRAS and annexin A2. Kwon and colleagues [35] reported that upregulated miR-29 in TGF- $\beta 1$-activated pancreatic stellate cells could reduce stromal deposition, cell viability, and cancer growth. These findings suggest that miRNAs play important roles in the molecular mechanism of PDAC. 


\section{Cellular Physiology Cell Physiol Biochem 2018;51:711-728 \begin{tabular}{ll|l} 
DOI: 10.1159/000495328 & (0) 2018 The Author(s). Published by S. Karger AG, Basel \\
and Biochemistry
\end{tabular} \\ Ta et al.: miR-1290 Promotes PDAC Aggressiveness by Targeting IKK1}

In the current study, miR-1290 played a role in promoting the proliferation, migration, and invasion of PDAC cell lines, whereas miR-1290 inhibitor suppressed these biological effects. Our in vivo experiments in nude mice also confirmed the in vitro results, suggesting that miR-1290 acts as an oncogene in the development of PDAC. Besides, the effect of miR1290 on promoting carcinogenesis in other cancers was previously observed ${ }^{29}$. miR-1290 and miR-1246 promote tumor growth and metastasis by suppressing metallothioneins in non-small cell lung cancer [36]. In gastric cancer, miR-1290 promotes cell proliferation and metastasis by targeting FOXA1[37]. Furthermore, we identified that IKK1 was a direct target of miR-1290 in PDAC cells, suggesting that miR-1290 promoted PDAC aggressiveness by interacting with IKK1.

IKK1 is a serine kinase essential for I $\kappa B$ phosphorylation and NF- $\kappa B$ activation in the $\mathrm{NF}-\kappa \mathrm{B}$ signaling pathway [38]. The NF- $\kappa \mathrm{B}$ signaling pathway is associated with diverse biological processes related to cell proliferation and differentiation, the immune response, and carcinogenesis [39]. In PDAC, NF- $\kappa B$ is constitutively activated in most patients and is linked to a KRAS mutation via the IKK1 complex [40, 41]. As a tumor-related gene, the role of IKK1 in nasopharyngeal carcinoma differentiation is complex [42]. Its expression is almost negative in keratinizing nasopharyngeal carcinoma but higher in non-keratinizing nasopharyngeal carcinoma [42]. In epidermal squamous cell carcinomas, IKK1 enhances human keratinocyte differentiation and regulates histological variants [43]. IKK1 is upregulated to control metastasis by repressing maspin in PDAC[44]. In a more recent study, Todoric et al [45] demonstrated that IKK1 deficiency induced p62 accumulation, leading to PDAC progression. The p62 function relies on the NRF2-driven induction of MDM2 and both the p53-dependent and -independent activity of MDM2, suggesting that IKK1 promotes PDAC aggressiveness through a non-NF- $\kappa B$ pathway. Here, we showed that overexpression of miR-1290 could suppress IKK1 in PDAC, suggesting that miR-1290 partially controls cell proliferation, invasion, and migration by inhibiting the expression of IKK1 via the p62/ NRF2/MDM2 pathway.

\section{Conclusion}

In summary, our study found that six miRNAs-miR-31-5p, miR-101-3p, miR-1290, miR-34a-3p, miR-21-5p, and miR-155-are significantly dysregulated in high-grade PanIN and PDAC compared with low-grade PanIN. Among these miRNAs, circulating miR-31$5 p$ and miR-1290 have potential diagnostic value in PDAC screening. The effect of miR1290 on pancreatic carcinogenesis was validated, with miR-1290 partially promoting cell proliferation, invasion, and migration by directly targeting the 3' UTR of IKK1. These results suggest that miR-1290 may act as an oncogene and that the miR-1290/IKK1/p62/NRF2 pathway may prove to be a potential target for the diagnosis and treatment of PDAC.

\section{Acknowledgements}

This work was partly supported by grants from the National Natural Science Foundation of China (Nos. 81172077 and 81772577) and the Shanghai Municipal Commission of Health and Family Planning, Key Developing Disciplines (No. 2015ZB0202).

\section{Disclosure Statement}

The authors declare no potential conflicts of interest. 


\section{Cellular Physiology Cell Physiol Biochem 2018;51:711-728 and Biochemistry \begin{tabular}{l|l} 
DOI: 10.1159/000495328 2018 The Author(s). Published by S. Karger AG, Basel \\
Publion
\end{tabular}

\section{References}

1 Chen W, Zheng R, Baade P, Zhang S, Zeng H, Bray F, Jemal A, Yu X, He J: Cancer statistics in China, 2015. CA Cancer J Clin 2016;66:115-132.

2 Poruk KE, Firpo MA, Adler DG, Mulvihill SJ: Screening for pancreatic cancer: why, how, and who? Ann Surg 2013;257:17-26.

-3 Basturk O, Hong SM, Wood LD, Adsay NV, Albores-Saavedra J, Biankin AV, Brosens LA, Fukushima N, Goggins M, Hruban RH, Kato Y, Klimstra DS, Kloppel G, Krasinskas A, Longnecker DS, Matthaei H, Offerhaus GJ, Shimizu M, Takaori K, Terris B et al.: A Revised Classification System and Recommendations From the Baltimore Consensus Meeting for Neoplastic Precursor Lesions in the Pancreas. Am J Surg Pathol 2015;39:1730-1741.

-4 Kanda M, Matthaei H, Wu J, Hong SM, Yu J, Borges M, Hruban RH, Maitra A, Kinzler K, Vogelstein B, Goggins M: Presence of somatic mutations in most early-stage pancreatic intraepithelial neoplasia. Gastroenterology 2012;142:730-733.e739.

-5 Kanda M, Sadakari Y, Borges M, Topazian M, Farrell J, Syngal S, Lee J, Kamel I, Lennon AM, Knight S, Fujiwara S, Hruban RH, Canto MI, Goggins M: Mutant TP53 in duodenal samples of pancreatic juice from patients with pancreatic cancer or high-grade dysplasia. Clin Gastroenterol Hepatol 2013;11:719-730. e715.

6 Lo ST, Pantazopouos P, Medarova Z, Moore A: Presentation of underglycosylated mucin 1 in pancreatic adenocarcinoma (PDAC) at early stages. Am J Cancer Res 2016;6:1986-1995.

7 Wei D, Wang L, Yan Y, Jia Z, Gagea M, Li Z, Zuo X, Kong X, Huang S, Xie K: KLF4 Is Essential for Induction of Cellular Identity Change and Acinar-to-Ductal Reprogramming during Early Pancreatic Carcinogenesis. Cancer Cell 2016;29:324-338.

8 Braun T, Gautel M: Transcriptional mechanisms regulating skeletal muscle differentiation, growth and homeostasis. Nat Rev Mol Cell Biol 2011;12:349-361.

-9 Shenoy A, Blelloch RH: Regulation of microRNA function in somatic stem cell proliferation and differentiation. Nat Rev Mol Cell Biol 2014;15:565-576.

10 Zhou S, Zhang S, Shen H, Chen W, Xu H, Chen X, Sun D, Zhong S, Zhao J, Tang J: Curcumin inhibits cancer progression through regulating expression of microRNAs. Tumour Biol 2017;39:1010428317691680.

11 Huang X, Zhi X, Gao Y, Ta N, Jiang H, Zheng J: LncRNAs in pancreatic cancer. Oncotarget 2016;7:5737957390.

12 Yonemori K, Kurahara H, Maemura K, Natsugoe S: MicroRNA in pancreatic cancer. J Hum Genet 2017;62:3340.

13 Teng Y, Ren Y, Hu X, Mu J, Samykutty A, Zhuang X, Deng Z, Kumar A, Zhang L, Merchant ML, Yan J, Miller DM, Zhang HG: MVP-mediated exosomal sorting of miR-193a promotes colon cancer progression. Nat Commun 2017;8:14448.

14 Lin HM, Mahon KL, Spielman C, Gurney H, Mallesara G, Stockler MR, Bastick P, Briscoe K, Marx G, Swarbrick A, Horvath LG: Phase 2 study of circulating microRNA biomarkers in castration-resistant prostate cancer. Br J Cancer 2017;116:1002-1011.

15 Huang H, Xiong G, Shen P, Cao Z, Zheng L, Zhang T, Zhao Y: MicroRNA-1285 inhibits malignant biological behaviors of human pancreatic cancer cells by negative regulation of YAP1. Neoplasma 2017;64:358-366.

-16 Rajabpour A, Rajaei F, Teimoori-Toolabi L: Molecular alterations contributing to pancreatic cancer chemoresistance. Pancreatology 2017;17:310-320.

17 Sun B, Liu X, Gao Y, Li L, Dong Z: Downregulation of miR-124 predicts poor prognosis in pancreatic ductal adenocarcinoma patients. Br J Biomed Sci 2016;73:152-157.

18 Cao Z, Liu C, Xu J, You L, Wang C, Lou W, Sun B, Miao Y, Liu X, Wang X, Zhang T, Zhao Y: Plasma microRNA panels to diagnose pancreatic cancer: Results from a multicenter study. Oncotarget 2016;7:41575-41583.

19 Hussein NA, Kholy ZA, Anwar MM, Ahmad MA, Ahmad SM: Plasma miR-22-3p, miR-642b-3p and miR-885$5 p$ as diagnostic biomarkers for pancreatic cancer. J Cancer Res Clin Oncol 2017;143:83-93.

20 Le Large TY, Meijer LL, Prado MM, Kazemier G, Frampton AE, Giovannetti E: Circulating microRNAs as diagnostic biomarkers for pancreatic cancer. Expert Rev Mol Diagn 2015;15:1525-1529. 


\section{Cellular Physiology Cell Physiol Biochem 2018;51:711-728 and Biochemistry \begin{tabular}{l|l} 
DOI: $10.1159 / 000495328$ & \\
(c) 2018 The Author(s). Published by S. Karger AG, Basel
\end{tabular}

-21 Miyamae M, Komatsu S, Ichikawa D, Kawaguchi T, Hirajima S, Okajima W, Ohashi T, Imamura T, Konishi H, Shiozaki A, Morimura R, Ikoma H, Ochiai T, Okamoto K, Taniguchi H, Otsuji E: Plasma microRNA profiles: identification of miR-744 as a novel diagnostic and prognostic biomarker in pancreatic cancer. Br J Cancer 2015;113:1467-1476.

22 du Rieu MC, Torrisani J, Selves J, Al Saati T, Souque A, Dufresne M, Tsongalis GJ, Suriawinata AA, Carrere N, Buscail L, Cordelier P: MicroRNA-21 is induced early in pancreatic ductal adenocarcinoma precursor lesions. Clin Chem 2010;56:603-612.

-23 Ryu JK, Hong SM, Karikari CA, Hruban RH, Goggins MG, Maitra A: Aberrant MicroRNA-155 expression is an early event in the multistep progression of pancreatic adenocarcinoma. Pancreatology 2010;10:66-73.

-24 Slater EP, Strauch K, Rospleszcz S, Ramaswamy A, Esposito I, Kloppel G, Matthai E, Heeger K, Fendrich V, Langer P, Bartsch DK: MicroRNA-196a and -196b as Potential Biomarkers for the Early Detection of Familial Pancreatic Cancer. Transl Oncol 2014;7:464-471.

-25 Khan S, Ebeling MC, Zaman MS, Sikander M, Yallapu MM, Chauhan N, Yacoubian AM, Behrman SW, Zafar N, Kumar D, Thompson PA, Jaggi M, Chauhan SC: MicroRNA-145 targets MUC13 and suppresses growth and invasion of pancreatic cancer. Oncotarget 2014;5:7599-7609.

26 Xue Y, Abou Tayoun AN, Abo KM, Pipas JM, Gordon SR, Gardner TB, Barth RJ, Jr., Suriawinata AA, Tsongalis GJ: MicroRNAs as diagnostic markers for pancreatic ductal adenocarcinoma and its precursor, pancreatic intraepithelial neoplasm. Cancer Genet 2013;206:217-221.

27 Imaoka H, Toiyama Y, Fujikawa H, Hiro J, Saigusa S, Tanaka K, Inoue Y, Mohri Y, Mori T, Kato T, Toden S, Goel A, Kusunoki M: Circulating microRNA-1290 as a novel diagnostic and prognostic biomarker in human colorectal cancer. Ann Oncol 2016;27:1879-1886.

28 Nagamitsu Y, Nishi H, Sasaki T, Takaesu Y, Terauchi F, Isaka K: Profiling analysis of circulating microRNA expression in cervical cancer. Mol Clin Oncol 2016;5:189-194.

-29 Li A, Yu J, Kim H, Wolfgang CL, Canto MI, Hruban RH, Goggins M: MicroRNA array analysis finds elevated serum miR-1290 accurately distinguishes patients with low-stage pancreatic cancer from healthy and disease controls. Clin Cancer Res 2013;19:3600-3610.

-30 Tape CJ, Ling S, Dimitriadi M, McMahon KM, Worboys JD, Leong HS, Norrie IC, Miller CJ, Poulogiannis G, Lauffenburger DA, Jorgensen C: Oncogenic KRAS Regulates Tumor Cell Signaling via Stromal Reciprocation. Cell 2016;165:910-920.

-31 Gore AJ, Deitz SL, Palam LR, Craven KE, Korc M: Pancreatic cancer-associated retinoblastoma 1 dysfunction enables TGF-beta to promote proliferation. J Clin Invest 2014;124:338-352.

32 Rucki AA, Foley K, Zhang P, Xiao Q, Kleponis J, Wu AA, Sharma R, Mo G, Liu A, Van Eyk J, Jaffee EM, Zheng L: Heterogeneous Stromal Signaling within the Tumor Microenvironment Controls the Metastasis of Pancreatic Cancer. Cancer Res 2017;77:41-52.

-33 Sano M, Driscoll DR, DeJesus-Monge WE, Quattrochi B, Appleman VA, Ou J, Zhu LJ, Yoshida N, Yamazaki S, Takayama T, Sugitani M, Nemoto N, Klimstra DS, Lewis BC: Activation of WNT/beta-Catenin Signaling Enhances Pancreatic Cancer Development and the Malignant Potential Via Up-regulation of Cyr61. Neoplasia 2016;18:785-794.

-34 Keklikoglou I, Hosaka K, Bender C, Bott A, Koerner C, Mitra D, Will R, Woerner A, Muenstermann E, Wilhelm $\mathrm{H}$, Cao Y, Wiemann S: MicroRNA-206 functions as a pleiotropic modulator of cell proliferation, invasion and lymphangiogenesis in pancreatic adenocarcinoma by targeting ANXA2 and KRAS genes. Oncogene 2015;34:4867-4878.

-35 Kwon JJ, Nabinger SC, Vega Z, Sahu SS, Alluri RK, Abdul-Sater Z, Yu Z, Gore J, Nalepa G, Saxena R, Korc M, Kota J: Pathophysiological role of microRNA-29 in pancreatic cancer stroma. Sci Rep 2015;5:11450.

-36 Zhang WC, Chin TM, Yang H, Nga ME, Lunny DP, Lim EK, Sun LL, Pang YH, Leow YN, Malusay SR, Lim PX, Lee JZ, Tan BJ, Shyh-Chang N, Lim EH, Lim WT, Tan DS, Tan EH, Tai BC, Soo RA et al.: Tumour-initiating cellspecific miR-1246 and miR-1290 expression converge to promote non-small cell lung cancer progression. Nat Commun 2016;7:11702.

37 Lin M, Shi C, Lin X, Pan J, Shen S, Xu Z, Chen Q: sMicroRNA-1290 inhibits cells proliferation and migration by targeting FOXA1 in gastric cancer cells. Gene 2016;582:137-142.

-38 Zandi E, Rothwarf DM, Delhase M, Hayakawa M, Karin M: The IkappaB kinase complex (IKK) contains two kinase subunits, IKKalpha and IKKbeta, necessary for IkappaB phosphorylation and NF-kappaB activation. Cell 1997;91:243-252. 


\section{Cellular Physiology Cell Physiol Biochem 2018;51:711-728

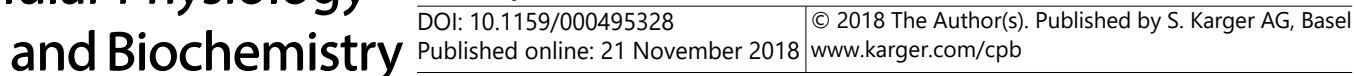

39 Gilmore TD: Introduction to NF-kappaB: players, pathways, perspectives. Oncogene 2006;25:6680-6684.

40 Wang W, Abbruzzese JL, Evans DB, Larry L, Cleary KR, Chiao PJ: The nuclear factor-kappa B RelA transcription factor is constitutively activated in human pancreatic adenocarcinoma cells. Clin Cancer Res 1999;5:119-127.

41 Prabhu L, Mundade R, Korc M, Loehrer PJ, Lu T: Critical role of NF-kappaB in pancreatic cancer. Oncotarget 2014;5:10969-10975.

42 Yan M, Zhang Y, He B, Xiang J, Wang ZF, Zheng FM, Xu J, Chen MY, Zhu YL, Wen HJ, Wan XB, Yue CF, Yang N, Zhang W, Zhang JL, Wang J, Wang Y, Li LH, Zeng YX, Lam EW, Hung MC, Liu Q: IKKalpha restoration via EZH2 suppression induces nasopharyngeal carcinoma differentiation. Nat Commun 2014;5:3661.

-43 Moreno-Maldonado R, Ramirez A, Navarro M, Fernandez-Acenero MJ, Villanueva C, Page A, Jorcano JL, Bravo A, Llanos Casanova M: IKKalpha enhances human keratinocyte differentiation and determines the histological variant of epidermal squamous cell carcinomas. Cell Cycle 2008;7:2021-2029.

44 Luo JL, Tan W, Ricono JM, Korchynskyi O, Zhang M, Gonias SL, Cheresh DA, Karin M: Nuclear cytokineactivated IKKalpha controls prostate cancer metastasis by repressing Maspin. Nature 2007;446:690-694.

-45 Todoric J, Antonucci L, Di Caro G, Li N, Wu X, Lytle NK, Dhar D, Banerjee S, Fagman JB, Browne CD, Umemura A, Valasek MA, Kessler H, Tarin D, Goggins M, Reya T, Diaz-Meco M, Moscat J, Karin M: StressActivated NRF2-MDM2 Cascade Controls Neoplastic Progression in Pancreas. Cancer Cell 2017;32:824839.e828. 